\title{
Cardiac rhythm and conduction before and after Mustard's operation for complete transposition of the great arteries
}

\author{
DAVID P SOUTHALL, BARRY R KEETON, RANJIT LEANAGE, LESLIE LAM, \\ MICHAEL C JOSEPH, ROBERT H ANDERSON, CHRISTOPHER R LINCOLN, \\ ELLIOT A SHINEBOURNE
}

From the Departments of Paediatric Cardiology and Cardiothoracic Surgery, Brompton Hospital, London

SUMMARY Between 1973 and 1978, 120 patients with transposition of the great arteries had a modification of Mustard's operation designed to avoid damage to the sinus and atrioventricular nodes. Of these, 88 had an atrial baffle alone from which nine hospital and four late deaths occurred (total mortality 14.8\%); 32 had additional closure of ventricular septal defect and/or relief of left ventricular outflow tract obstruction from which six hospital and three late deaths occurred $(28 \%)$.

On the standard electrocardiogram, 101 of 105 patients $(96 \%)$ discharged from hospital were in sinus rhythm, but of the four patients with arrhythmias two had conduction abnormalities before operation. A further two patients with complex procedures had acquired bifascicular block. Twenty-fourhour electrocardiograms in 19 patients who had both pre- and postoperative recordings showed acquired arrhythmias in one of 13 who had simple Mustard's operation and in two of six who had additional procedures. Of a further 39 patients who had only postoperative 24-hour recordings, three of 30 with a simple operation and three of nine with additional surgical procedures had arrhythmias that were thought to be acquired.

Rhythm patterns and rates previously considered to be surgically acquired were found before operation on 24-hour electrocardiograms in patients with complete transposition and have now been reported to occur in normal infants and children. There is thus no evidence to support the view that such episodes with the electrocardiographic patterns of Wenckebach, 2:1 or complete sinuatrial block, atrial premature beats of less than 12 per hour, or intermittent junctional escape rhythms represent acquired cardiac arrhythmias.

Seven of the 22 deaths occurred after leaving hospital and included five which were sudden and unexpected, no adequate cause being found at necropsy. Four of these had conduction disorders or arrhythmias on standard and 24-hour electrocardiograms including three with complex procedures.

Our results indicate that a modified Mustard's operation may reduce the frequency of surgically acquired arrhythmias.

Arrhythmias occurring after interatrial repair, Mustard's operation ${ }^{1}$ of complete transposition of the great arteries (concordant atrioventricular and discordant ventriculoarterial connections) have been widely reported. ${ }^{2-4}$ Standard 12 lead electrocardiograms have shown persistent arrhythmias in onetenth to two-thirds of patients. ${ }^{3-5}$ Saalouke et al. ${ }^{6}$ showed abnormal sinus node function in 63 per cent Received for publication 5 July 1979 and abnormal atrial effective refractory periods in 33 per cent of patients studied by intracardiac electrophysiological techniques. Saalouke et al. ${ }^{6}$ and Goodwin et al..$^{7}$ also detected arrhythmias in 100 per cent of patients using 24-hour Holter monitoring.

Arrhythmias found after Mustard's operation have been variously explained by damage to the sinus node or its artery,,$^{358}$ to the atrioventricular node, ${ }^{4}$ to the postulated 'specialised internodal 
pathways', ${ }^{9}$ or to a combination of these.

At the Brompton Hospital one surgeon has used a standardised technique specifically designed to avoid nodal damage, but making no attempt to preserve the postulated specialised internodal pathways. A review of the postoperative standard electrocardiograms from patients having this modified operation revealed fewer arrhythmias than did studies reported by other workers. In order to evaluate this further, we have examined pre- and postoperative standard electrocardiograms and both pre- and postoperative 24-hour electrocardiograms whenever possible on patients undergoing Mustard's operation. The results of both the standard and 24-hour recordings form the subject of this report.

\section{Patients, surgical techniques, and methods}

One hundred and twenty patients aged between 2 weeks and 8 years were operated upon at the Brompton Hospital by one surgeon. Of these, 96 patients had undergone a previous balloon atrial septostomy, three patients had had atrial septectomies, and 21 patients had had neither procedure. Eighty-eight patients had placement of an atrial baffle alone (simple Mustard's operation). In four this was a palliative procedure, a ventricular septal defect being left open because of the presence of pulmonary vascular obstructive disease. There were 13 deaths in this group (14.8\% mortality), four of whom had pulmonary vascular disease. Of these deaths, nine were perioperative and four were late deaths after discharge from hospital. Thirty-two patients had additional closure of ventricular septal defect and/or relief of left ventricular outflow tract obstruction (complex Mustard's operation), and nine died (six early and three late deaths, total mortality $28 \%$ ). Standard 12 lead electrocardiograms were recorded before operation in all patients from both groups and after operation on the 105 patients who left hospital. Follow-up recordings were made on 69 patients at three months, 63 patients at six months, 51 at one year, 41 at two years, and 28 at three to four years after operation. Twenty-four-hour electrocardiograph tape recordings were performed on a total of 58 patients; 19 had both pre- and postoperative recordings and included 13 with simple and six with complex transposition. Twenty-four-hour recordings were made at times ranging from two weeks to four years after the operation and more than one recording was made on the majority of subjects. These patients were unselected and their inclusion in this part of the study depended upon the availability of recorders at the time of hospital attendances or on the frequency of outpatient attendances. Eight patients were discharged to the care of doctors in other countries and their postoperative electrocardiograms are not available. To the best of our knowledge none of this latter group of patients has died.

In the interpretation of the 24-hour electrocardiographic data we have taken account of normal values obtained from the 24-hour electrocardiographic study of 134 healthy neonates, ${ }^{10}$ and 92 healthy schoolchildren aged between 7 and 12 years, without congenital heart disease. ${ }^{11}$ Atrial premature beats of less than 12 per hour have been shown to be frequently present in infancy 101213 and were therefore not considered in this report to be abnormal. Electrocardiographic patterns indistinguishable from Wenckebach sinuatrial block, 2:1 sinuatrial block, or complete sinuatrial block and intermittent junctional escape rhythms have also been described as 'normal' findings on 24-hour electrocardiograms in healthy infants and schoolchildren. ${ }^{10} 11$ Nevertheless, to allow comparison with other reports their occurrence is documented in the results section.

\section{RECORDING AND ANALYSIS}

Twenty-four-hour recordings were performed on a Medilog cassette recorder* using two electrodes (Simonsen and Weel, silver chloride electrode type 810) one placed high over the right sternal border and the other in the V6 position in the left axilla. The 24-hour tapes were analysed directly by a trained technician using a playback system and arrhythmia detector. ${ }^{\star}$ The recorder and analyser incorporated a synclock system which, by providing a reference time signal, ensured that possible variations in tape speed did not produce artefactual measurements of rhythm or rate.

\section{SURGICAL TECHNIQUE (Fig. 1)}

A constant technique was employed in each patient for cannulation and insertion of the atrial baffle. Cardiopulmonary bypass with moderate or profound hypothermia with circulatory arrest was used in these patients. The heart was approached through a median sternotomy and the ascending aorta cannulated. The superior vena cava was cannulated through the right atrial appendage and the inferior vena cava at its junction with the right atrium. Where circulatory arrest was used a single venous cannula was placed into the right atrium through the appendage. The encircling snare for the superior vena cava was always placed well cephalad to its junction with the atrium. The right atrial incision passed from the area of the atrial appendage coronally towards the junction of the upper and lower right pulmonary veins and across the crista ^Oxford Instrument Company. 


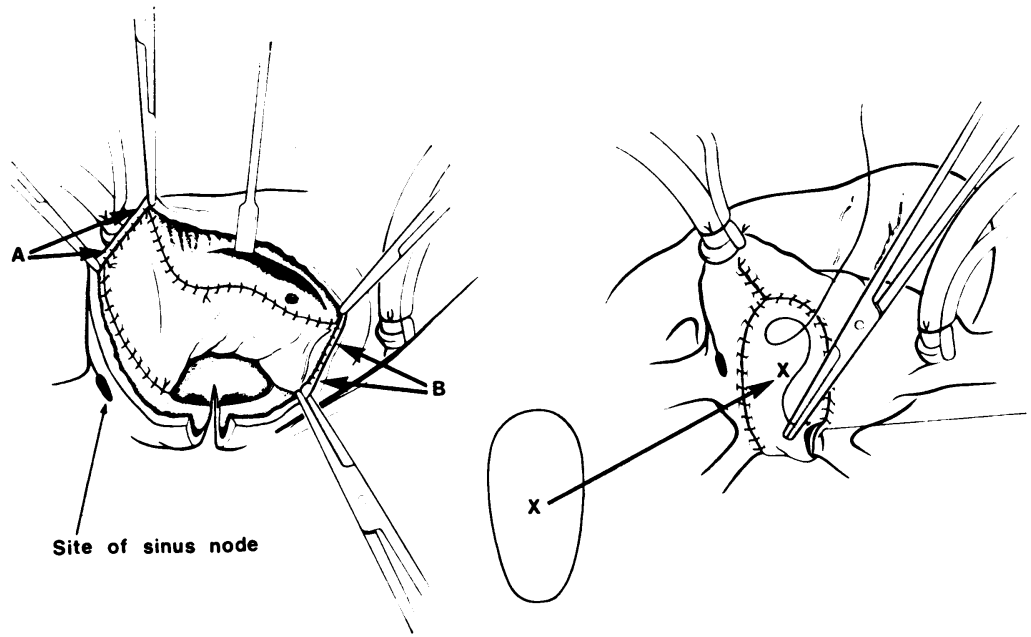

Fig. 1 Intra-operative drawing for the interatrial baffle operation for correction of transposition of the great arteries. The incision in the right atrium is coronal and extends onto the back wall of the left atrium. (A) points to the attachment of the baffle in the region of the superior vena caval orifice. It has been sutured to the cut edge of the atriotomy. (B) points to the attachment of the baffle in the region of the inferior vena caval orifice, once again to the cut edge of the atriotomy. (X) An enlarging patch is placed in the lower part of the atriotomy thereby increasing the size of the pulmonary venous atrium.

terminalis. The interatrial septum was widely excised particularly in the region of the superior limbus of the fossa ovalis. The interatrial baffle of thin Dacron cloth was trouser-shaped after the design of G. Brom (1975, personal communication). The pulmonary venous atrium was enlarged by extending the incision between the upper and lower right pulmonary veins round on to the posterior left atrial wall and inserting a patch of woven Dacron or autologous material. The coronary sinus was left intact draining to the new pulmonary venous atrium. The suture lines for the baffle attachment were placed superior to the coronary sinus; the periphery of the attachment of the baffle was placed well away from the ostia of the superior and inferior vena cavae and incorporated the cut edge of the atriotomy. Continuous sutures were used throughout. Closure of the ventricular septal defect in the majority of cases was effected through the tricuspid valve. Some patients, particularly those with an infundibular septal or immediately subaortic defect required a right ventriculotomy placed high in the infundibulum. Left ventricular to pulmonary artery valved conduits were used to relieve severe cases of subvalvar pulmonary stenosis in five patients.

\section{Results}

(A) STANDARD ELECTROCARDIOGRAPHIC DATA (Table 1)

Before operation, 119 of 120 patients were found to be in sinus rhythm on a standard 12 lead electrocardiogram.

Of the $105(96 \%)$ postoperative patients discharged from hospital, 101 remained in sinus rhythm with normal atrioventricular conduction on the standard electrocardiogram. Of the four patients not in sinus rhythm, one, who was not on treatment,

Table 1 Arrhythmias or conduction disorders on standard electrocardiograms found in six of 105 patients discharged from hospital after operation

\begin{tabular}{|c|c|c|c|c|}
\hline \multirow[b]{2}{*}{$\begin{array}{l}\text { Case } \\
\text { no. }\end{array}$} & \multirow[b]{2}{*}{ Operation } & \multicolumn{2}{|c|}{ Electrocardiogram } & \multirow[b]{2}{*}{ Outcome } \\
\hline & & Preoperative & Postoperative & \\
\hline 1 & Simple & $\begin{array}{l}1^{\circ} \mathrm{AV} \text { block } \\
\text { PR } 0.24 \mathrm{~s}\end{array}$ & $\begin{array}{l}\text { Complete AV } \\
\text { block QRS } \\
0.06 \mathrm{~s}\end{array}$ & Late death \\
\hline 2 & Simple & $\begin{array}{l}\text { Complete AV } \\
\text { block }\end{array}$ & $\begin{array}{l}\text { Complete AV } \\
\text { block QRS } \\
0.08 \mathrm{~s}\end{array}$ & Well \\
\hline 3 & $\begin{array}{l}\text { Complex } \\
\text { (previous } \\
\text { septectomy, } \\
\text { transatrial } \\
\text { VSD repair) }\end{array}$ & $\begin{array}{l}\text { Normal } \\
\text { conduction } \\
\text { r) }\end{array}$ & Atrial fibrillation & Well \\
\hline 4 & Complex & $\begin{array}{l}\text { Normal } \\
\text { conduction }\end{array}$ & $\begin{array}{l}\text { Complete AV } \\
\text { block QRS } \\
0.08 \mathrm{~s}\end{array}$ & Pacemaker \\
\hline 5 & $\begin{array}{l}\text { Complex } \\
\text { (transatrial } \\
\text { VSD repair) }\end{array}$ & $\begin{array}{l}\text { Normal } \\
\text { conduction }\end{array}$ & $\begin{array}{l}\text { RBBB }+ \text { LAD } \\
\left(-90^{\circ}\right)\end{array}$ & Late death \\
\hline 6 & Complex & $\begin{array}{l}\text { Normal } \\
\text { conduction }\end{array}$ & $\underset{\left(-135^{\circ}\right)}{\text { RBBB }}$ & Late death \\
\hline
\end{tabular}

AV, atrioventricular; LAD, left axis deviation; RBBB, right bundle-branch block. 
had first degree atrioventricular conduction delay preoperatively, with a PR interval of $0.24 \mathrm{~s}$. After operation this patient had complete atrioventricular block with a QRS duration of $0.06 \mathrm{~s}$, and died suddenly five months after operation. Another patient developed complete heart block (QRS 0.08 s) during preoperative cardiac catheterisation. Despite persistence of this rhythm postoperatively, the patient has remained well (follow-up for four years, no pacemaker). Both these patients had a Mustard's operation alone.

Two others who had complex procedures developed arrhythmias-one atrial fibrillation and the other complete atrioventricular block (QRS $0.08 \mathrm{~s}$ ); the latter required permanent pacemaker insertion because of Adams-Stokes attacks. Two further patients undergoing complex procedures were in sinus rhythm after operation but had bifascicular block pattern on the electrocardiogram (complete right bundle-branch block and axes of $-90^{\circ}$ and $-135^{\circ}$, respectively); both were sudden late deaths.

(B) 24-HOUR ELECTROCARDIOGRAPHIC DATA (1) Pre- and postoperative data (Table 2 and 3)

Three of 19 patients $(16 \%)$ had abnormalities of rhythm after operation, which were not present before; one out of 13 had simple Mustard's operation and two out of six had had a complex procedure.
In the one patient with Mustard's operation alone multiple ( 60 per hour) atrial premature beats were present. Of the two patients undergoing complex procedures, one had very frequent atrial premature beats ( 700 per hour) and the other had bouts of probable ventricular tachycardia (rate 280 per minute) (Fig. 2). Heart rates between 40 and 50 per minute, junctional escape rhythms, electrocardiographic patterns of 2:1 Wenckebach and complete sinuatrial block (Fig. 3), and atrial premature beats of less than 12 per hour were

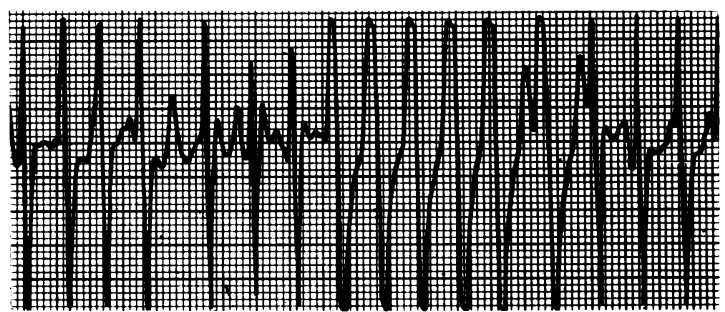

Fig. 2 24-hour electrocardiogram showing a probable ventricular tachycardia at 280/minute. The sixth beat represents either capture or fusion; there is no constant relation between the $Q R S$ during the tachycardia and the $P$ waves; the $Q R S$ is broad ( 0.12 seconds) and ventricular premature beats were found in other parts of the recording.

Table 2 Pre-and postoperative 24-hour electrocardiograph results on 19 patients who had Mustard's operation

\begin{tabular}{|c|c|c|c|c|c|}
\hline \multirow{2}{*}{ Subject } & \multirow{2}{*}{$\begin{array}{l}\text { Age at } \\
\text { operation }\end{array}$} & \multicolumn{2}{|l|}{ Preoperative } & \multicolumn{2}{|l|}{ Postoperative } \\
\hline & & Rhythm & Lowest rate & Rhythm & Lowest rate \\
\hline \multicolumn{6}{|c|}{ Simple operations } \\
\hline 7 & 10 days & $\begin{array}{r}\text { SAW, J 2:1 SAB } \\
\text { APBs }(<12 / h)\end{array}$ & $\geqslant 50$ & SAW, J 2:1 SAB & $\geqslant 50$ \\
\hline 8 & 21 days & Sinus & $\geqslant 50$ & Sinus & $\geqslant 50$ \\
\hline 9 & 3 months & APBs $(<12 / \mathrm{h})$ & $\geqslant 50$ & $\operatorname{APBs}(<12 / \mathrm{h})$ & $\geqslant 50$ \\
\hline 10 & 8 months & $2: 1 \mathrm{SAB}$ & $\geqslant 50$ & Sinus & $\geqslant 50$ \\
\hline 11 & 10 months & Complete SAB SAW, J (Fig. 3) & $\geqslant 50$ & $\operatorname{APBs}(<12 / \mathrm{h})$ & $\geqslant 50$ \\
\hline 12 & 11 months & SAW & $\geqslant 50$ & SAW & $\geqslant 50$ \\
\hline 13 & 15 months & SAW, J 2:1 SAB & $45-49$ & SAW, J 2:1 SAB (Fig. 5, 6, 7) & ) $35-39$ \\
\hline 14 & 16 months & SAW & $\geqslant 50$ & $\begin{array}{l}\text { SAW, J } \\
\text { APBs }(<12 / h)\end{array}$ & $\geqslant 50$ \\
\hline 15 & 18 months & Sinus & $\geqslant 50$ & Sinus & $\geqslant 50$ \\
\hline 16 & 18 months & APBs $(<12 / h)$ & $\geqslant 50$ & J & $\geqslant 50$ \\
\hline 17 & 2 years & Sinus & $\geqslant 50$ & Sinus & $\geqslant 50$ \\
\hline 18 & 2 years & SAW, J & $40-44$ & SAW, J & $\geqslant 50$ \\
\hline 19 & 7 years & $\mathbf{J}$ & $\geqslant 50$ & APBs $(60 / h)$ & $\geqslant 50^{\star}$ \\
\hline \multicolumn{6}{|c|}{ Complex operations } \\
\hline 20 & 6 months & APBs $(<12 / \mathrm{h})$ & $\geqslant 50$ & APBs $(<12 / \mathrm{h})$ & $\geqslant 50$ \\
\hline & 9 months & Sinus & $\geqslant 50$ & SAW, J & $\geqslant 50$ \\
\hline 22 & 4 years & Sinus & $\geqslant 50$ & VT $(300 / \min )$ (Fig. 2) & $\geqslant 50^{\star}$ \\
\hline 23 & 5 years & SAW, J & $\geqslant 50$ & Sinus & $\geqslant 50$ \\
\hline 24 & 6 years & SAW & $\geqslant 50$ & SAW & $45-49$ \\
\hline 25 & 7 years & SAW, J & $\geqslant 50$ & SAW, J & $\geqslant 50^{\star}$ \\
\hline
\end{tabular}

APB, atrial premature beat; $J$, intermittent junctional escape rhythm; ${ }^{\star}$, considered to be 'abnormal', acquired arrhythmias; SAB, ECG patterns indistinguishable from sinuatrial block or sinus arrest; SAW, sinuatrial Wenckebach block; VT, ventricular tachycardia 
present in the 19 patients as frequently before as after the operation (Table 2) and were not classified as 'abnormal' cardiac arrhythmias. One child in whom the rate was 45 to 50 per minute before operation had a rate of 35 to 40 per minute one year after operation.

(2) Additional postoperative data

(a) Simple Mustard's operation (Table 4). Of 30 patients studied, three had abnormal arrhythmias $(10 \%)$. These consisted of episodes of supraventricular tachycardia in two patients with additional atrioventricular block in one case (Fig. 4) and multiple atrial premature beats in the third. A further patient who had intermittent complete atrioventricular block before operation was shown to have a similar rhythm after operation with no episodes of asystole. Twenty-two had intermittent junctional escape rhythms, 23 had

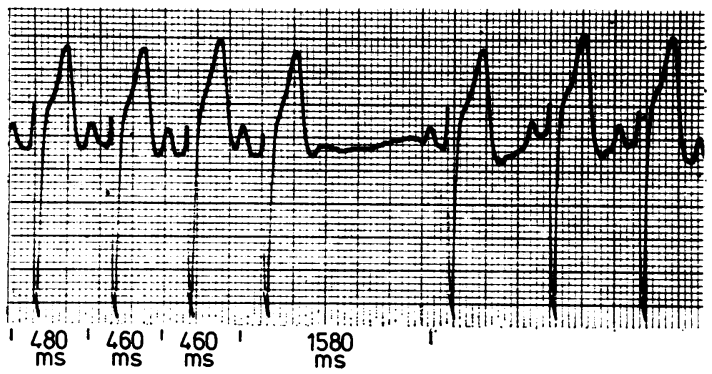

Fig. 3 24-hour electrocardiogram showing an electrocardiographic pattern indistinguishable from complete (third degree) sinuatrial block or sinus arrest. There is a sudden lengthening of $P P$ interval by more than twice the preceding PP intervals. The escape beat is probably sinus in origin. Similar rhythm patterns are found on 24-hour electrocardiograms of normal infants and children.

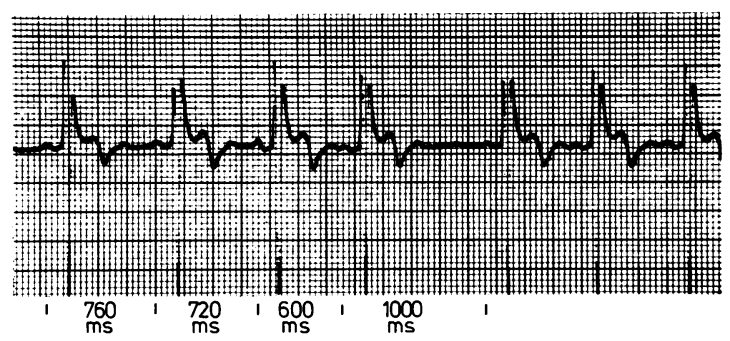

Fig. 5 24-hour electrocardiogram showing a pattern indistinguisable from sinuatrial $W$ enckebach block (second degree). There is a progressive diminution of PP intervals before a pause which is between 50 and 90 per cent longer than the previous PP interval. The beat immediately preceding the pause is unlikely to have been an atrial extrasystole because in the illustration the coupling interval is long and the pattern was repeatedly seen with more obviously normal $P$ waves at other times during the recording. Similar rhythm patterns were found on 24-hour electrocardiograms of normal infants and children.

Table 3 Comparison of pre- and postoperative 24-hour electrocardiographic data on 19 subjects

\begin{tabular}{lll}
\hline & \multicolumn{2}{c}{ Number of subjects } \\
\cline { 2 - 3 } & Before operation & After operation \\
\hline Sinus rhythm & 5 & 5 \\
$\begin{array}{l}\text { Intermittent junctional escape } \\
\text { rhythm }\end{array}$ & 7 & 7 \\
$\begin{array}{l}\text { Electrocardiographic patterns } \\
\text { of sinuatrial block }\end{array}$ & 10 & 8 \\
$\begin{array}{l}\text { APBs }<12 / \mathrm{h} \\
\text { APBs }>12 / \mathrm{h}^{\star}\end{array}$ & 4 & 4 \\
Ventricular tachycardia & 0 & 2 \\
Lowest heart rate $>50$ & 17 & 1 \\
Lowest heart rate 45-49 & 1 & 1 \\
Lowest heart rate 40-44 & 1 & 0 \\
Lowest heart rate 35-39 & 0 & 1 \\
\hline
\end{tabular}

*, considered to be 'abnormal' arrhythmias.

APB, atrial premature beat.
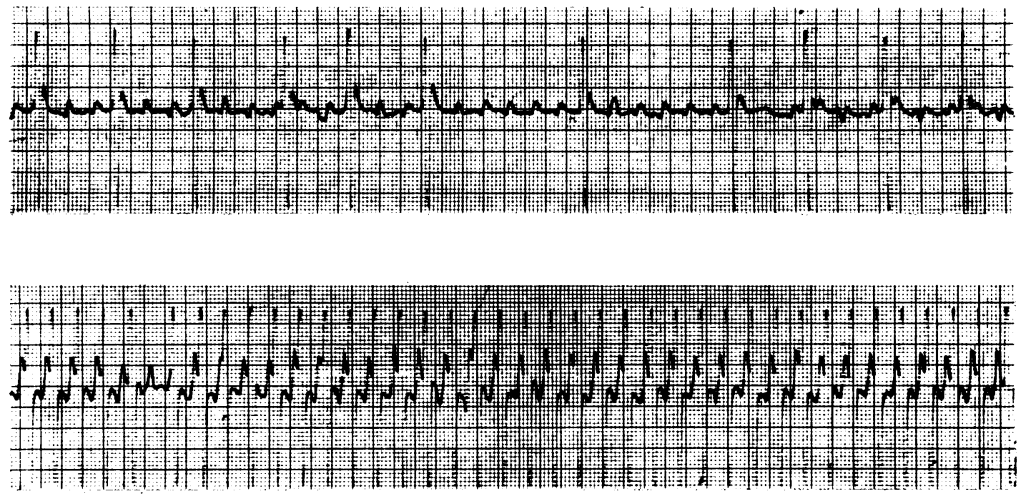

Fig. 4 24-hour electrocardiogram showing a supraventricular tachycardia of 300/minute (upper and lower panels), with episodes of atrioventricular block (upper panel). This child was not receiving digoxin. 


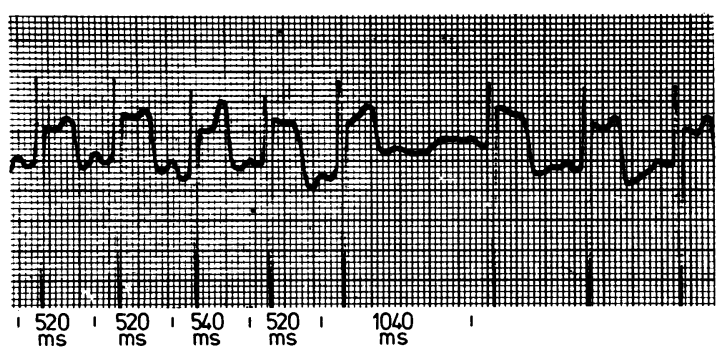

Fig. 6 24-hour electrocardiogram showing a pattern indistinguishable from $2: 1$ (second degree) sinuatrial block. Similar rhythm patterns are found on 24-hour electrocardiograms of normal infants and children.

Table 4 Additional postoperative 24-hour electrocardiographic results on 30 patients who had simple Mustard's operation

\begin{tabular}{|c|c|c|c|}
\hline \multirow{2}{*}{$\begin{array}{l}\text { No. of } \\
\text { patients }\end{array}$} & \multicolumn{2}{|l|}{ Postoperative } & \multirow[b]{2}{*}{ Age at 24-hour recording } \\
\hline & Rhythm & Lowest rate & \\
\hline 4 & $\begin{array}{l}\text { Continuous sinus } \\
\text { rhythm }\end{array}$ & 50 & $12,18,28,30$ months \\
\hline 1 & J & 50 & 28 months \\
\hline 3 & SAW & 50 & $13,22,31$ months \\
\hline 1 & SAW & $45-49$ & 3 years \\
\hline 7 & SAW, J & 50 & $1 \frac{1}{2}, 1 \frac{1}{2}, 2,5,6,6,7$ years \\
\hline 4 & SAW, J & $45-49$ & $3,4,7,8$ years \\
\hline 1 & SAW, J & $40-44$ & 4 years \\
\hline 1 & SAW, J & $35-39$ & 3 years \\
\hline 1 & $2: 1 \mathrm{SAB}$ & 50 & 3 years \\
\hline 2 & $\begin{array}{l}\text { SAW, J } \\
\text { APBs }(<12 / h)\end{array}$ & 50 & 3,7 years \\
\hline 1 & $\begin{array}{l}\text { SAW, J } \\
\text { APBs }(<12 / h)\end{array}$ & $35-39$ & 4 years \\
\hline 1 & SVT $260 / \mathrm{min}$ plus & & 7 years* \\
\hline 1 & $\begin{array}{l}\text { SVT } \\
\text { SAW, J }\end{array}$ & 50 & 3 years * \\
\hline 1 & CAVB & $45-49$ & 4 years $^{\star} t$ \\
\hline 1 & $\begin{array}{l}\text { APBs }(>12 / \mathrm{h}) \\
\text { SAW, J }\end{array}$ & 50 & 18 months ${ }^{\star}$ \\
\hline
\end{tabular}

$\star$, considered to be abnormal arrhythmias; $t$, also present on standard ECG pre- and postoperatively; AV, atrioventricular; APB, atrial premature beats; CAVB, complete atrioventricular block; $\mathrm{J}$, intermittent junctional escape rhythm; SAB, ECG pattern indistinguishable from sinuatrial block; SAW, ECG pattern indistinguishable from sinuatrial Wenckebach block; SVT, supraventricular tachycardia. electrocardiographic patterns of sinuatrial Wenckebach block (Fig. 5), one had electrocardiographic patterns of 2:1 sinuatrial block (Fig. 6), eight had rates between 40 and 50 per minute, and two had rates between 35 and 40 per minute (Fig. 7).

(b) Mustard's operation complicated by other procedures (Table 5 ). Of the nine patients studied, three had acquired arrhythmias (33\%); multiple ventricular premature beats with couplets in one (Fig. 8), multiple atrial premature beats (30 per hour) in another, and bouts of supraventricular trachycardia in the third. In addition, six had intermittent junctional escape rhythms, six had electrocardiographic patterns indistinguishable from sinuatrial Wenkebach block, one had atrial premature beats of less than 12 per hour, three had rates between 45 and 50 per minute, and one had a rate of between 35 and 40 per minute.

In summary, of a total of 43 patients $(13+30)$ who had a simple Mustard's operation, four had what could be considered abnormal arrhythmias (9\%) on 24-hour recordings, and of the 15 patients (six plus nine) studied who had additional procedures five had abnormal arrhythmias (33\%).

\section{(3) Artefact problems}

A common problem when analysing the 24-hour electrocardiogram was to differentiate sinus tachycardias from arrhythmias. There were two main reasons for this difficulty. Firstly, at high heart rates $P$ waves were often obscured and the single lead nature of the recording did not help. Secondly changes in electrode contact leading to variation in QRST configuration gave the appearance of aberrant ventricular conduction (Fig. 9); measurement of RR intervals before and after the onset of QRST wave changes may help interpretation.

(C) DEATHS (Table 6)

Twenty-two $(18 \%)$ of the 120 patients have died and seven of these were late deaths. Two of these late deaths were associated with pulmonary

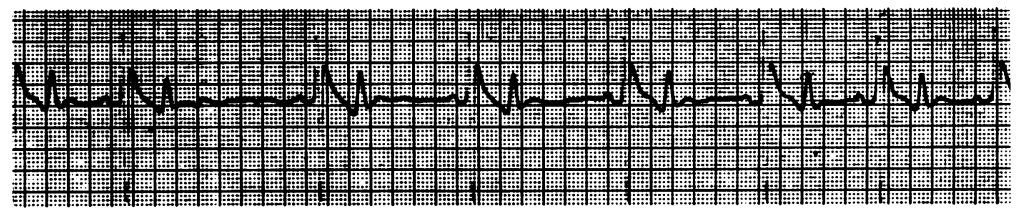

Fig. 7 24-hour electrocardiogram showing sinus bradycardia of 39/minute (as measured over five beats) and including an $R R$ interval of 1.80 seconds. The biphasic $T$ wave is an artefact of the playback unit of the analyser. Similar rates were found in the 24-hour electrocardiograms of normal children aged 7 to 12 years. 

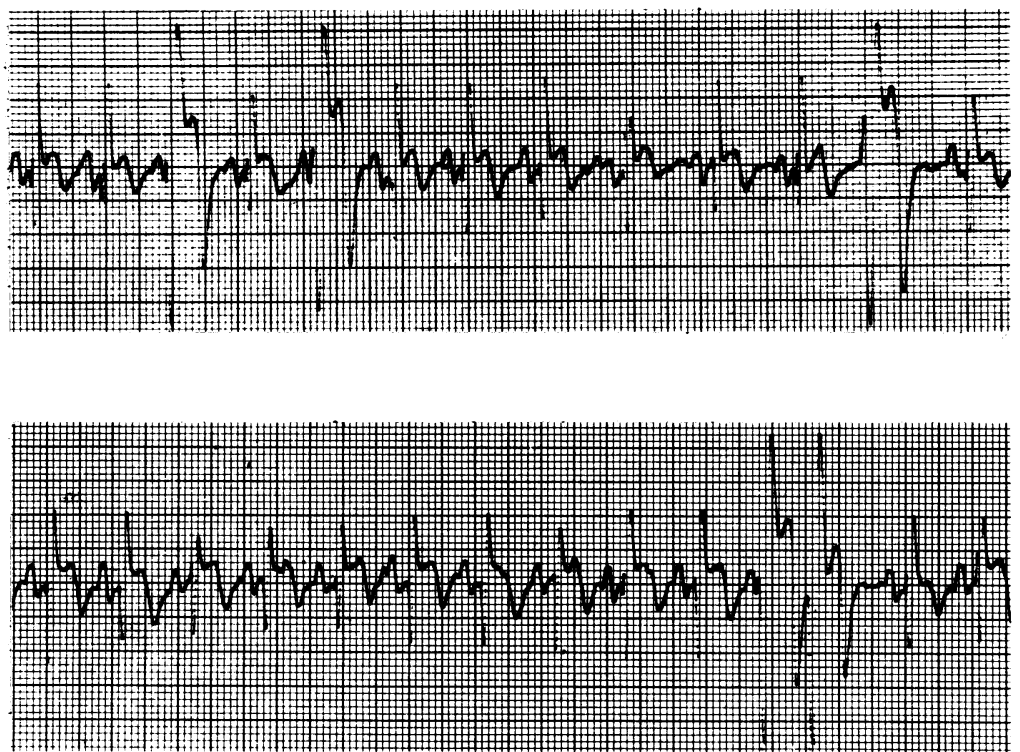

Fig. 8 24-hour electrocardiogram showing frequent ventricular premature beats with two in succession at the end of the recording. There is no relation between these premature beats and the $P$ waves; there is a constant coupling interval ( 0.4 seconds), and the $Q R S$ configuration is abnormal with $S T$ and $T$ wave changes.

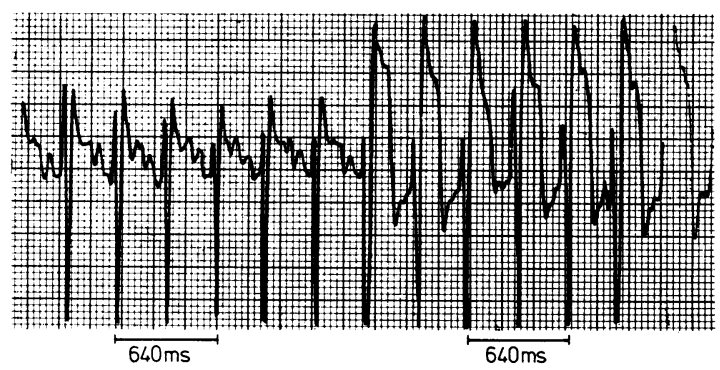

Fig. 9 24-hour electrocardiogram showing spontaneous variation in $S T$ wave configuration giving the superficial appearance of a tachyarrhythmia. There is no change in rate but the $P$ wave is obscured by an increase in the low frequency $T$ wave. This phenomenon is common and probably results from changes in electrode contact. vascular disease, but five patients, with an apparently good surgical result, died suddenly and unexpectedly with no adequate cause found at necropsy. Four of these five had conduction disturbances or arrhythmias documented on standard or 24-hour electrocardiograms while the fifth patient had a normal standard electrocardiogram but had not been studied on a 24-hour tape. The three patients dying after complex Mustard's operation all had conduction abnormalities on standard or 24-hour electrocardiograms in contrast to one of the two patients (without pulmonary vascular disease) dying after simple Mustard's operation. As previously indicated in this patient, a conduction disorder (PR interval 0.24 s) had been present before operation.

Table 5 Additional postoperative 24-hour electrocardiograph results on nine patients who had complicated Mustard's operation

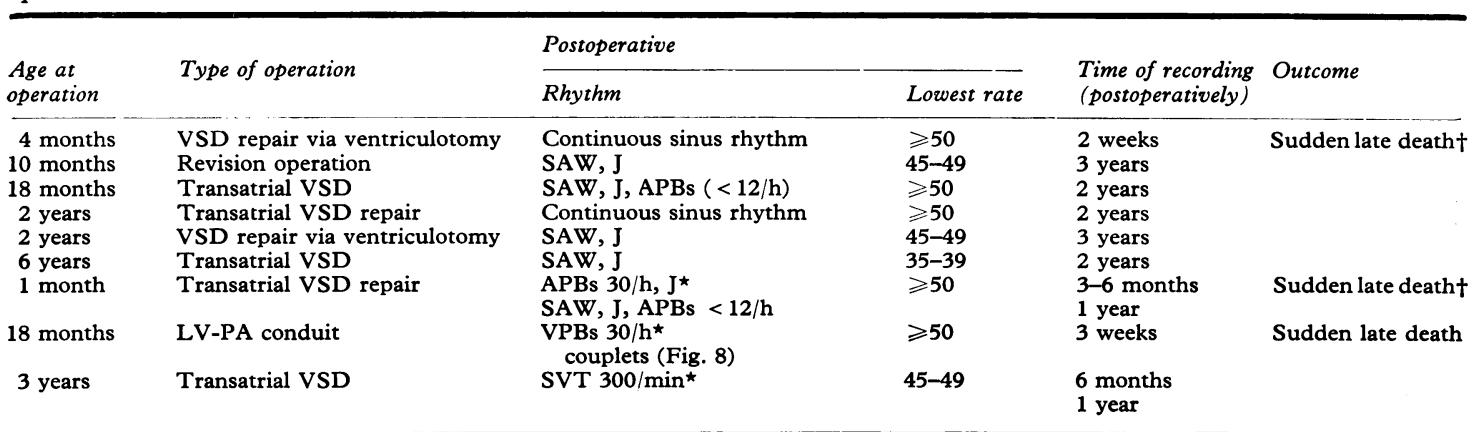

*, abnormal arrhythmias; APB, atrial premature beats; J, intermittent junctional escape rhythm; SAW, electrocardiographic patterns indistinguishable from sinuatrial Wenckebach block; SVT, supraventricular tachycardia; VPB, ventricular premature beats. tRBBB and LAD also present. 


\section{Discussion}

The incidence of arrhythmias and other conduction abnormalities after Mustard's operation for transposition of the great arteries has previously been reported to be between 13 and 100 per cent. ${ }^{2}{ }^{6}$ In this study we found that 101 of 105 patients who survived the early postoperative period were in sinus rhythm on standard electrocardiography after a modified Mustard's operation designed to avoid the sinus node and atrioventricular conduction tissues.

Furthermore, one of the four patients not in sinus rhythm had complete atrioventricular block before operation and another first degree atrioventricular block, so that of patients discharged from hospital whose preoperative standard electrocardiogram showed sinus rhythm and normal atrioventricular conduction, 98 per cent were in sinus rhythm postoperatively.

A standard 12 lead electrocardiogram, however, records only a small period of time. Twenty-fourhour electrocardiograms, as previously described in other studies, ${ }^{67}$ are the most effective means of detecting and quantifying arrhythmias after Mustard's operation. We were not surprised, therefore, to find more arrhythmias in our series using this technique. Thus in 43 patients whose standard electrocardiograms showed sinus rhythm after simple Mustard's operation, 24-hour recordings showed additional acquired arrhythmias in four ( $9 \%$, confidence limits 2 to $22 \%$ ). However, in 15 who had complex procedures an additional five patients showed acquired arrhythmias on 24-hour recordings ( $33 \%$, confidence limits 12 to $62 \%$ ). There seems to be a real difference in the occurrence of arrhythmias on 24-hour recordings in simple and complex Mustard's procedures. However, perhaps because the numbers are small, this is not supported by statistical analysis $\left(P<0.10, x^{2}=3.237\right)$. Of the 19 patients in the groups who had both pre- and postoperative 24-hour recordings, acquired and abnormal arrhythmias were detected in one of 13 having simple Mustard's operation alone and in two of six undergoing complex procedures.

It is most important when analysing 24-hour electrocardiograms not to ascribe all arrhythmias detected to surgical intervention, as have others. ${ }^{67} \mathrm{We}$ have recently reported the occurrence and patterns of arrhythmias on the 24-hour electrocardiogram in 134 normal healthy neonates, ${ }^{10}$ and have additional data $^{11}$ on 92 healthy schoolchildren. Table 7 shows that electrocardiographic patterns indistinguishable from sinuatrial Wenckebach block, 2:1, and complete sinuatrial block, junctional escape rhythms, and atrial premature beats of less than 12 per hour are frequently found in the normal population.

Similarly, in Table 7 we have documented episodes of bradycardia described in the normal population which have heart rates previously interpreted by other workers (when found after Mustard's operation) as being acquired and abnormally slow. These findings in healthy infants and children are similar to those of Brodsky et al. ${ }^{14}$ who showed similar rhythm patterns and rate variations in healthy adults.

The relatively few acquired arrhythmias in our postoperative patients are not only the result of excluding certain rhythm and rate patterns on the grounds that they occur in the normal population, or that they are present before operation. The low prevalence appears to be related to certain aspects of the surgical approach. For instance, the techniques of cannulation of superior and inferior vena cavae and the suturing of the periphery of the baffle to the cut edge of the atriotomy are designed

Table 6 Seven late deaths after simple and complex Mustard's operation on 120 children

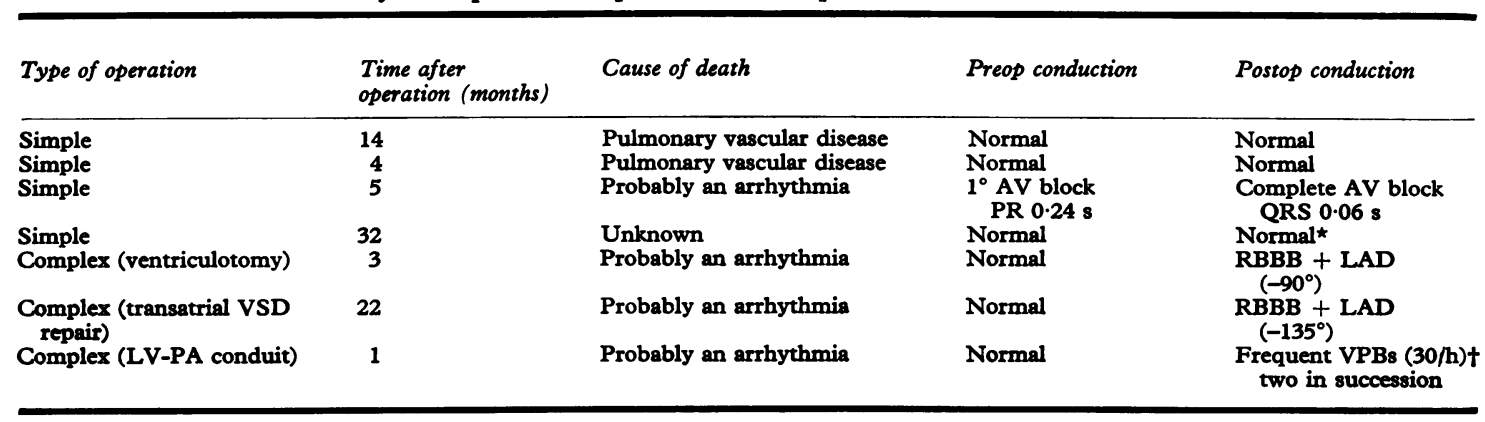

^, no 24-hour electrocardiographic recording; $t$, on 24-hour electrocardiographic recording; AV, atrioventricular; RBBB, right bundlebranch block; LAD, left axis deviation; VPB, ventricular premature beats. 
Table 7 Summary of 24-hour electrocardiographic findings on healthy neonates aged 1 to 14 days and healthy children aged 7 to 11 years

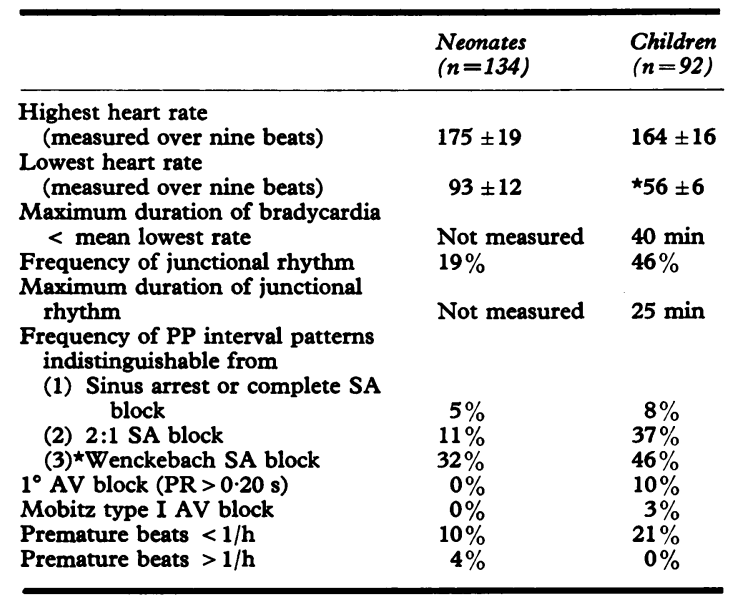

to avoid damage to the sinus and atrioventricular nodes as well as to their blood supply. The advantages of these techniques have previously been stressed by others. ${ }^{414} 15$ In some reports, the high incidence of atrial arrhythmias after Mustard's operation has been attributed to transection of purported specialised internodal conduction pathways believed to be present in the atrial walls. ${ }^{16}$ The operation used in our patients involves a long coronal incision throughout most of the right and part of the left atrial wall transecting the crista terminalis. In addition, most of the atrial septum is removed. Despite this, after operation a large majority of our patients are in sinus rhythm with normal atrioventricular conduction. This is consistent with the view that discrete specialised pathways are not present ${ }^{17} 18$ but that conduction from the sinus node to the atrioventricular node occurs through 'working' atrial myocardium.

It is significant that four of the seven late deaths in our series were sudden and associated with arrhythmias or conduction disorders. Pulmonary vascular disease associated with intercurrent illness accounted for two further deaths. Both patients with bifascicular block pattern on the postoperative electrocardiogram died suddenly. This indicated the need for further electrophysiological studies in patients acquiring this conduction abnormality postoperatively. Thus we agree with El Said et al. ${ }^{5}$ that intracardiac electrophysiological studies are indicated in all patients after Mustard's operation with conduction disorders on the standard electrocardiogram pre- or postoperatively. Permanent pacemaker implantation may be necessary in some.
In our opinion if the true prevalence of dangerous late arrhythmias is to be determined, 24-hour electrocardiograms should be recorded on all postoperative patients.

Our study suggests that by using a modification of Mustard's operation, ${ }^{19}$ postoperative conduction disorders and arrhythmias may be largely avoided. In diagnosing these arrhythmias, normal data from healthy children should be taken into account. None the less, despite the low incidence of arrhythmias in our series, some of the sudden late deaths, particularly those associated with complex procedures, appear to result directly from acquired arrhythmias and may well be preventable.

Dr Southall is supported by a grant from the Board of Governors of the Brompton Hospital, National Heart and Chest Hospitals. The 24-hour electrocardiographic equipment was supplied by the British Heart Foundation. We would like to thank Dr Prudence Mitchell for helping with the analysis of the 24-hour recordings.

\section{References}

${ }^{1}$ Mustard WT, Keith, JD, Trusler GA, Fowler R, Kidd L. Surgical management of transposition of the great vessels. F Thorac Cardiovasc Surg 1964; 48: 9538.

${ }^{2}$ El Said G, Rosenberg HS, Mullins CE, Hallman G, Cooley DA, McNamara DG. Dysrhythmia after Mustard's operation for transposition of the great arteries. Am F Cardiol 1972; 30: 526-32.

${ }^{3}$ Clarkson PM, Barratt-Boyes BG, Neutze JM. Late dysrhythmias and disturbance of conduction following Mustard's operation for complete transposition of the great arteries. Circulation 1976; 53: 519-24.

${ }^{4}$ Lewis $\mathrm{AB}$, Lindesmith GG, Takahashi $\mathrm{M}$, et al. Cardiac rhythm following the Mustard procedure for transposition of the great vessels. $\mathcal{F}$ Thorac Cardiovasc Surg 1977; 73: 919-26.

${ }^{5}$ El Said G, Gillette PC, Cooley DA, Mullins CS, McNamara DG. Protection of the sinus node in Mustard's operation. Circulation 1976; 53: 788-91.

'Saalouke MG, Rios G, Perry LW, Shapiro SR, Scott LP. Electrophysiologic studies after Mustard's operation for D-transposition of the great vessels. Am f Cardiol 1978; 41: 1104-9.

${ }^{7}$ Goodwin AW, Reid DS, Braidwood L, Tynan M. Arrhythmias after Mustard's operation. Abstracts, 7th European Congress of Cardiology, 20-25, VI 1976; 772.

${ }^{8}$ Gillette PC, El Said GM, Sivarajan N, Mullins CE, Williams RL, McNamara DG. Electrophysiological abnormalities after Mustard's operation for transposition of the great arteries. Br Heart $\mathcal{F} 1974$; 36: 186-91. ${ }^{9}$ Isaacson R, Titus JL, Merideth J, Feldt RH, McGoon DC. Apparent interruption of atrial conduction pathways after surgical repair of transposition of the great arteries. Am F Cardiol 1972; 30: 533-5. 
${ }^{10}$ Southall DP, Richards JM, Johnston PGB, Shinebourne EA. Study of cardiac rhythm in healthy newborn infant (abstract). Br Heart f 1979; 41: 382.

"Southall DP, Johnston F, Richards JM, Shinebourne EA, Johnston PGB. Study of heart rate and rhythm in normal schoolchildren (abstract). Br Heart $\mathcal{F}$ 1979; 42: 234 .

${ }^{12}$ Southall DP, Vulliamy DG, Davies MJ, Anderson RH, Shinebourne EA, Johnson AM. A new look at the neonatal electrocardiogram. $\mathrm{Br} M e d \mathcal{F} 1976$; 2: 615-8.

${ }^{13}$ Southall DP, Orrell MJ, Talbot JF, et al. Study of cardiac arrhythmias and other forms of conduction abnormality in newborn infants. $\mathrm{Br} \mathrm{Med} \mathcal{F} 1977$; 2: 597-9.

${ }^{14}$ Brodsky M, Wu D, Denes P, Kanakis C, Rosen KM. Arrhythmias documented by 24 hour continuous electrocardiographic monitoring in 50 male medical students without apparent heart disease. Am $\mathcal{F}$ Cardiol 1977; 39: 390-5.

${ }^{15}$ Ebert PA, Gay WA Jr, Engle MA. Correction of transposition of the great arteries. Ann Surg 1974; 180: 433-7.

${ }^{16}$ Lev M, Bharti S. Anatomy of the conduction system in normal and congenitally abnormal hearts. In: Roberts NK, Gelbrand H, eds. Cardiac arrhythmias in the neonate, infant and child. New York: AppletonCentury Crofts, 1977: 29.

${ }^{17}$ Janse MJ, Anderson RH. Specialised internodal atrial pathway: fact or fiction. Eur f Cardiol 1974; 2: 117-36.

${ }^{18}$ Turley K, Ebert PA. Total correction of transposition of the great arteries: conduction disturbances in infants younger than three months of age. $\mathcal{F}$ Thorac Cardiovasc Surg 1978; 76: 312-8.

${ }^{19}$ Ullal RR, Anderson RH, Lincoln CR. Mustard's operation modified to avoid dysrhythmias and pulmonary and systemic venous obstruction. $\mathcal{f}$ Thorac Cardiovasc Surg 1979; 78: 431-9.

Requests for reprints to Christopher Lincoln, Esq., FRCS, Brompton Hospital, London SW3 6HP. 